MATEC Web of Conferences 40, 02007 (2016)

DOI: $10.1051 /$ matecconf $/ 20164002007$

(C) Owned by the authors, published by EDP Sciences, 2016

\title{
Sand Particles Impact on the Tribological Behavior of Sliding Contact
}

\author{
Saud Aldajah , Mohammed Alrawadeh
}

Abu Dhabi Polytechnic, Electromechanical Engineering Department, P. O. Box 111499, Abu Dhabi, UAE

\begin{abstract}
Lubricant contaminants cause severe problems to machines. Substantial research has been conducted to study the impact of such contaminates on the tribological performance of lubricated contacts. The primary goal of such studies is to find solutions to avoid the dirtiest cause of damaging machines' parts and to reduce energy consumption and maintenance costs. The current study investigates the tribological behavior of contaminated lubricated contacts; the contaminants considered in this research are sand particles. The effect of the sand particles concentration levels on friction and wear of a tribological system under sliding contact was studied. Three different concentration levels were tested; $5 \%, 10 \%$ and $15 \%$. The experimental program was carried out using an in-house built ball on disc machine at room temperature, constant normal load, constant speed, constant running time and constant travelling distance. Results showed that both friction coefficient and wear volume of the contacting surfaces are dependent on the concentration level of the sand particles. Both friction coefficient and wear volume increased by increasing the sand particles concentration. SEM was utilized to study the wear mechanisms of the contacting surfaces, it was found that the dominant wear mechanism in all cases was abrasive wear.
\end{abstract}

\section{Introduction}

Tribology is the science and technology of interacting surfaces in relative motion. It studies the principles of friction, wear and lubrication [1]. The importance of studying tribology is crucial for many machines and vehicles, in which there are surfaces rubbing against each other. One of the main factors that influence friction and wear is the presence of contaminations in the lubricated contacts. Such contaminations include wear debris, soot and sand particles. Sand particles are considered more harmful for vehicles and machines that operate in the desert. Vehicles and machines that operate in sandy environments are vulnerable to sand particles entering and becoming entrapped between their mechanical parts, causing abrasive wear. Since sand particles are relatively hard, and because of their small particles size, it is difficult to prevent them from entering into machines. Many researchers have done experimental as well as theoretical studies to explore the effects of sand particles on such machines. Several theoretical models where developed to calculate two-body abrasive wear, which arises because of the sliding movement of a hard and rough surface, or embedded particles over a softer surface [2-5]. However, these models do not suffice when abrasion is caused by particles that are able to move freely between the surfaces in sliding contact. There was some effort that has been done to model this three-body abrasive wear. Torrance used wedge wear tests to relate the abrasive wear resistance to strain to failure [4]. Fang et al. applied Monte Carlo simulations for generating a layer of spherical abrasive particles [6] and combined the
Manson-Coffin equation for low-cycle fatigue [7] with Miner's rule of linear cumulative damage [8] to calculate the wear loss of the generated particle layers. Xie and Bhushan [9] derived a wear index for polishing based on the particle size, the hardness of both the polishing pad and the polished surface and the contact pressure, to calculate the wear rate during polishing. The relations between the sand particle properties and abrasion are yet to be defined. The particle size effect on abrasion has been well acknowledged and studied [9-14]. The wear rate increases with increasing abrasive medium size, up to around 100 micrometer [12]. several studies conducted in this field considering different parameters. Nathan et al. [15], considered the effect of abrasive size on wear. The authors studied the correlation between variation of volume of wear, effect of variation of diameter of abrasive particles of SIC (35 to $710 \mu \mathrm{m}$ ), load $(0.5-6$ $\mathrm{kg})$, speed of abrasion $(0.032-2.5 \mathrm{~m} / \mathrm{sec})$, and distance traveled (1.5 -6 m). Figure 1 shows these research results. They concluded that the wear volume is linearly proportional with abrasive particles' size up to $70 \mu \mathrm{m}$, while the gradient decreases continuously between $70 \mu$ $\mathrm{m}$ and $150 \mu \mathrm{m}$, and above $150 \mu \mathrm{m}$ the correlation is linear relationship.

This work studies the effect of sand particle concentrations on the friction and wear of a sliding contact. Sand was collected from the UAE desert, with variations in particle size and shape. Experimental program was carried out using an in-house built ball on disc machine at the following constant parameters: room temperature, normal load, speed, running time, track 
radius and travelling distance. The experimental materials (ball and disc) were 440 stainless steel, the discs were polished carefully using Sample Fine Rotary Grinder (up to 600 mesh grinding sand paper).Stainless steel was chosen because most of the components that get exposed to sand are the bearings and other components in rotating machinery which are made from stainless steel.. The sand particles were sieved to determine their size range. A fixed diameter range $(75-125 \mu \mathrm{m})$ was chosen in order to eliminate the size effect; The concentration levels were tested are $5 \%, 10 \%$ and $15 \%$..

\section{Experimental Program and Setup}

The experimental program of the present work consists of testing a total of twenty stainless steel samples. The experimental program was divided into two main groups according to the investigated cases. The test specimens of first group (group I) was considered as reference specimens that subjected to fresh oil only "eight specimens". Second group (group II) of specimens was to investigate the effect of different size of sand particles "twelve specimens under the following size range: (75125) $\boldsymbol{\mu} \mathrm{m},(125-150) \boldsymbol{\mu} \mathrm{m}$ and (150-300) $\boldsymbol{\mu} \mathrm{m}$ ". Before each test, all surfaces of stainless steel samples were prepared and tested via SEM, to make sure that the surfaces are very well polished. Samples were polished using Sample Fine Rotary Grinder Machine up to 600 mesh grinding paper. In addition, sand particles used during the tests had been prepared using special type of screens to get the target range of diameters.

To get the required size-range of sand particles, two micron mesh screens (75 and $125 \mu \mathrm{m})$ were used over each other. In addition, the lubricant was SAE 20W/50 API SERVICE, SL/CF ACEA A3/02/B3 available from ADNOC- UAE. All oil-sand mixtures in this type were prepared by adding fixed size particles (75-125) $\mu \mathrm{m}$ diameter and changing the concentration of the sand particles. (four samples for each: 5\%sand-95\%oil, $10 \%$ sand-90\%oil and 15\%sand-85\%oil) (weight percent). Then, each mixture was mixed together manually right at the beginning of each test. Figure 1 shows SEM for the sand particles for Sand particles range 75-125 $\mu \mathrm{m}$.

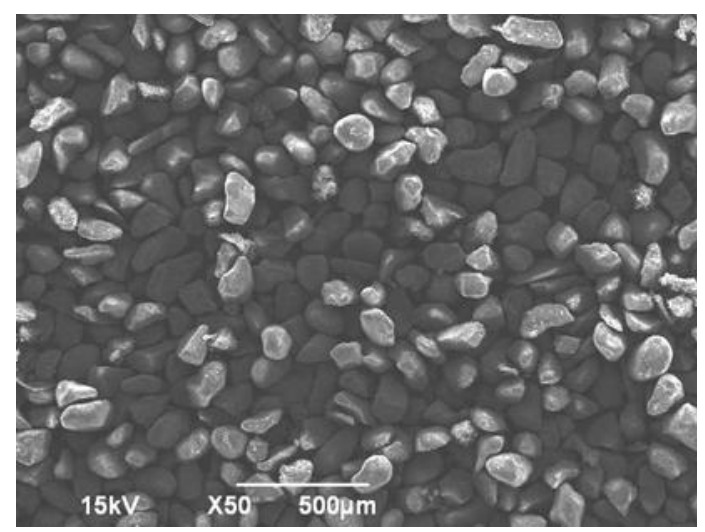

Figure 1. SEM for $75-125 \mu \mathrm{m}$ average diameter range of sand particles.
The apparatus used in this experimental study is ball on disc Testing, the same as outlined by ASTM G99-04, ball-on-disc testing consists of a rotating disc in contact with a fixed ball with a spherical top as shown in figure 2 .

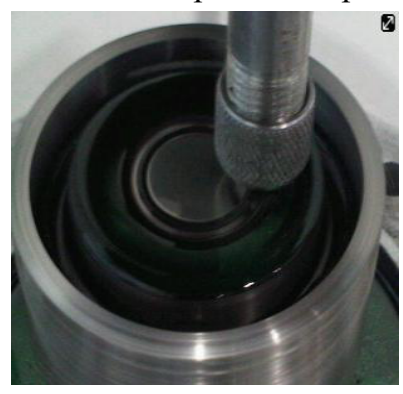

Figure 2. Ball on Disk Testing Machine.

The system consists of arm to which the load cell is attached, a fixture which accommodates discs up to 137 $\mathrm{mm}$ in diameter and $35 \mathrm{~mm}$ thick. The cup-like (housing) enclosed fixture permits the use of liquid lubricants during a wear test. an electronic force sensor "S-type load cell " for measuring the friction force, and a computer software "lab view" for displaying and storing data for analysis. DC motor driven turntable up to $70 \mathrm{rpm}$.

During this research, turntable speed, the normal load and any other desired test variable such as friction limit and number of rotation were specified. A pre-determined Hertzian pressure is automatically applied to the ball using a system of weights. Rotating the turntable while applying this force to the ball includes sliding wear as well as a friction force.

All parts of ball on disc testing device were manufactured from stainless steel. The device consists of a ball carrier assembly attached to one side of S-type load cell, while the other side of load cell is fixed on a steel arm connecting to the nearest wall. The balls used in this work were fixed by a ball holder, and attached to the end of the pin. The rotary part is a disc carrier assembly which is directly attached to controlled DC motor. The speed of motor was adjusted manually by variable resistance, while a digital speedometer has been used to measure the speed before and during the experiments. In addition, the specimens are secured by a three bolts " $120^{\circ}$ between them" and centered inside the disc holder. The whole system was aligned carefully to maintain the effect of normal force always perpendicular to the disc.

The ball assembly consists of three parts: pin, ball holder, stainless steel balls with $12.7 \mathrm{~mm}$ diameter. The ball assembly is pivoted to the frame so that it will move up and down. The load cell mounted to the rear end of the pin carrier frame measures the friction force exerted to on the pin during the rotation. In addition, the disc carrier assembly is basically two parts, one of them is the disc itself and the other is the sample holder.

Sliding distance and Time were kept constant in all conducted experiments. The wear track radius and rotational speed were also fixed for all Tests. All experiments were done at room temperature, and carried out with constant normal load. All constant experimental parameters are shown in Table 1. 
Table 1. Experimental Constant Parameters.

\begin{tabular}{|l|l|l|}
\hline Parameter & Unit & Value \\
\hline Ball diameter & $\mathrm{mm}$ & 12.7 \\
\hline Disc size(diameter) & $\mathrm{mm}$ & 137 \\
\hline Time & second & 3600 \\
\hline Disc rotation & $\mathrm{rpm}$ & 70 \\
\hline Normal load & $\mathrm{N}$ & 50.2 \\
\hline Average Hertizan stress & $\mathrm{MPa}$ & 600 \\
\hline Travelling distance & $\mathrm{m}$ & 330 \\
\hline Track Radius & $\mathrm{mm}$ & 12.5 \\
\hline Temperature & $\begin{array}{l}\text { Room Temperature } \\
\left(22^{\circ} \mathrm{C}\right)\end{array}$ \\
\hline
\end{tabular}

\section{RESULTS AND DISCUSSION}

The presence of solid particles in lubricant is inevitable. These undesirable particles cause wear by abrasion, fatigue or adhesion with surface in sliding contact.. The average surface roughness for the samples had been tested was $0.075 \mu \mathrm{m}$ measured by Surface Roughness Tester, and the hardness measured by Micro Hardness Tester was 282.2 HV. The evaluation of friction coefficient was at running time of 3600 seconds at constant normal load of $50.2 \mathrm{~N}$, constant rotational speed of $70 \mathrm{rpm}$, and constant travelling distance of $330 \mathrm{~m}$ and constant wear track radius of $12.5 \mathrm{~mm}$.

12 specimens had been tested for this group. All tests were done using the same range of sand particles size (75-125 $\mu \mathrm{m})$, the variation was in the concentration only (5\%,10\% and $15 \% \mathrm{wt}$ ). All the results of friction coefficient were compared with the control samples results which tested using fresh oil only without any contaminants. Figure 3 shows the variation for friction coefficients of stainless steel samples for different tests by varying the concentration of sand particles at room temperature. The friction appears that the highest friction coefficient is at $15 \%$ concentration of sand particles (average $\mu$ is $0.184 \pm 0.0047783$ ), whereas the lowest one is for that samples with $5 \%$ concentration (average $\mu$ is $0.13376 \pm 0.00199$ ), while that samples had been tested without sand particles "fresh oil only "the average $\mu$ is $0.1125 \pm 0.0010939801)$. Therefore, the friction coefficient is proportional to the concentration of sand particles. These variations can be explained by the entry of more particles into the contact which accelerates friction. On other hand, the friction coefficients are time independent, it reach steady state after 250 seconds (5 minutes) approximately.

Figure 4 shows the average value of friction coefficients for each test for $75-125 \mu \mathrm{m}$ diameter of sand particles at different concentrations.

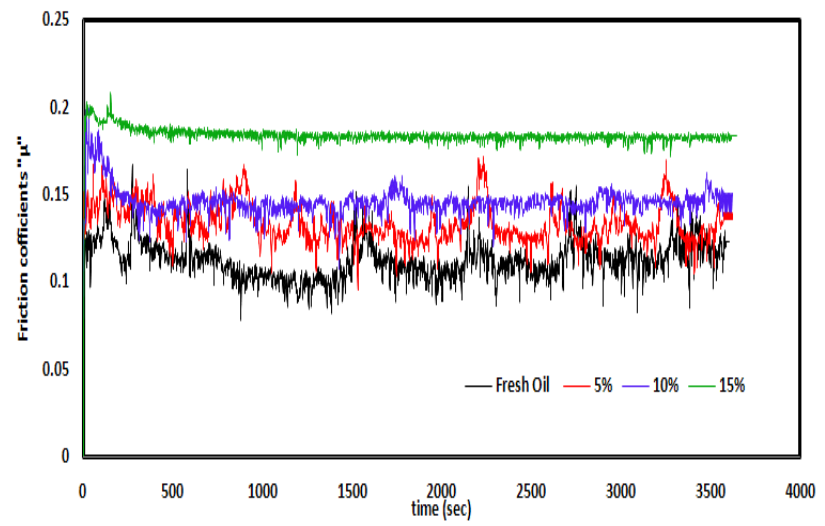

Figure 3. Average Friction Coefficient Behavior for Lubricant Containing Various Concentrations of Sand Particles.

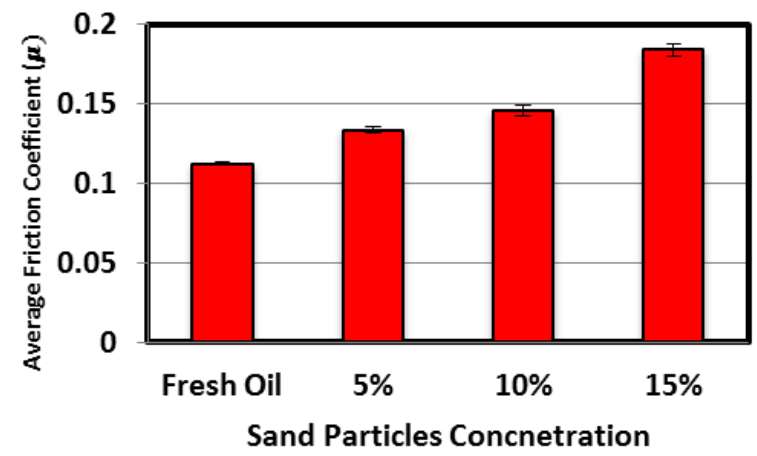

Figure 4. Average friction coefficients for $75-125 \mu \mathrm{m}$ average diameter under concentration variation of sand particles.

Figures 5 and 6 show the wear volume results for the disc and ball for this type of testing. The specimens that had been tested in absented of sand particles has the lowest wear volume for both ball and disc (wear volume of the ball is $0.000049371 \pm 0.000008 \mathrm{~mm}^{3}$ and for the disc is $0.0876 \pm 0.0019 \mathrm{~mm}^{3}$ ), whereas the increasing in sand particles concentration will increase the wear volume for both the ball and disc. Indeed, the results show that the wear volume for the disc is $0.4489 \pm$ $0.01056 \mathrm{~mm} 3$ for $5 \% \mathrm{wt}$ of sand particles, increasing to $0.0489 \pm 0.01056 \mathrm{~mm} 3$ for $10 \%$ wt and $0.9877 \pm 0.00954$ $\mathrm{mm} 3$ for $15 \%$ wt of sand particles. In addition, the wear volume for the ball is $0.0059 \pm 0.000262 \mathrm{~mm} 3$ for $5 \% \mathrm{wt}$ of sand particles, increasing to $0.0101 \pm 0.000186 \mathrm{~mm} 3$ for $10 \% \mathrm{wt}$ and $0.0152 \pm 0.000248 \mathrm{~mm} 3$ for $15 \%$ wt of sand particles.

For better understanding of wear in this type of test, photo-micrographic images of steel ball and disc were taken using SEM. Fig. 7 characterizes the disc without the presence of contaminants. Figures 8 and 9 give detailed pictures of the surfaces and balls under $5 \%, 10 \%$ and $15 \%$ of contaminants. This wear is accelerated by the presence of sand particles. In the presence of sand particles and furrows is noteworthy for operating with higher concentration of contaminants. 
MATEC Web of Conferences

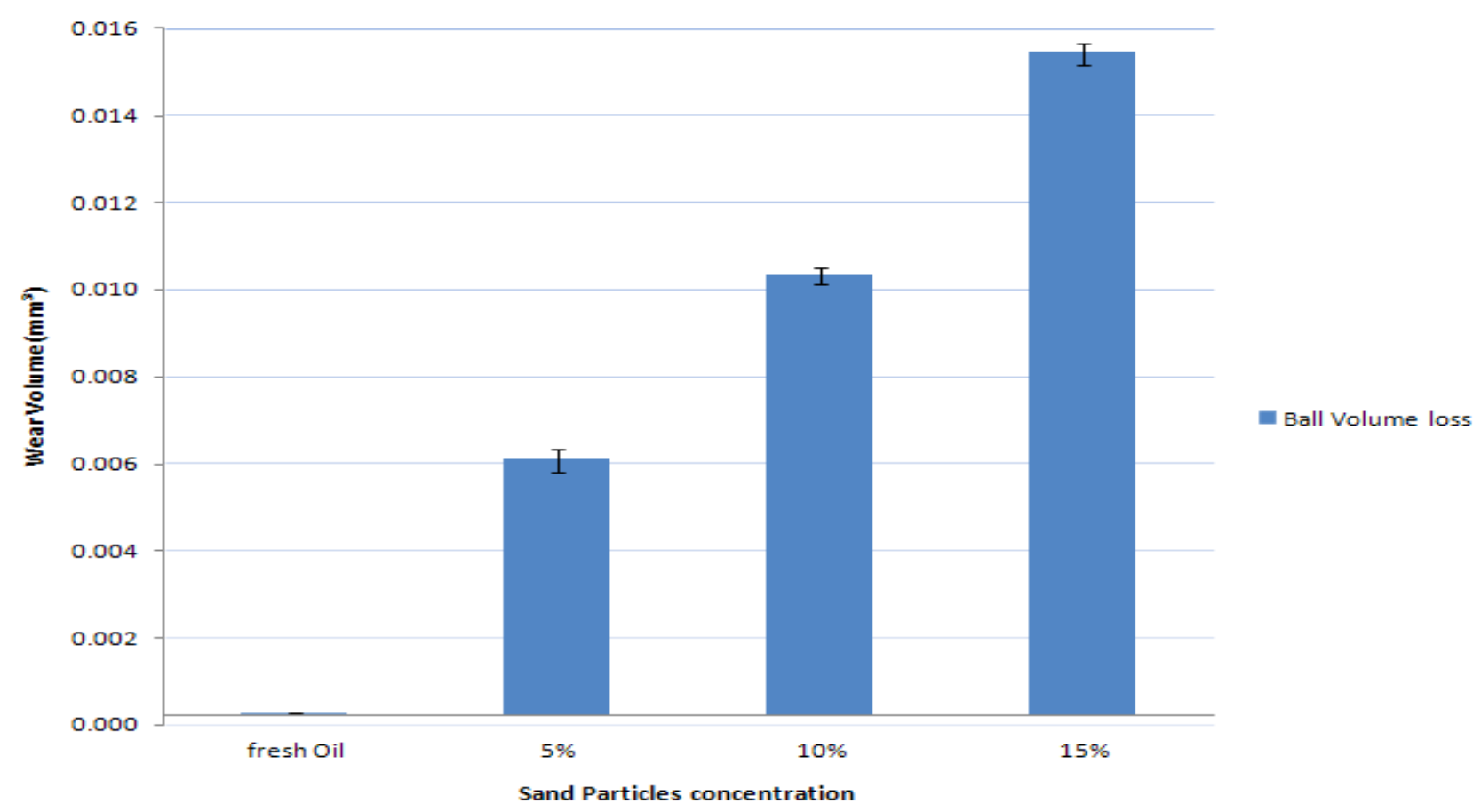

Figure 5. Wear Results for the Balls for $75-125 \mu \mathrm{m}$ Size Range, under concentration variation of sand particles.

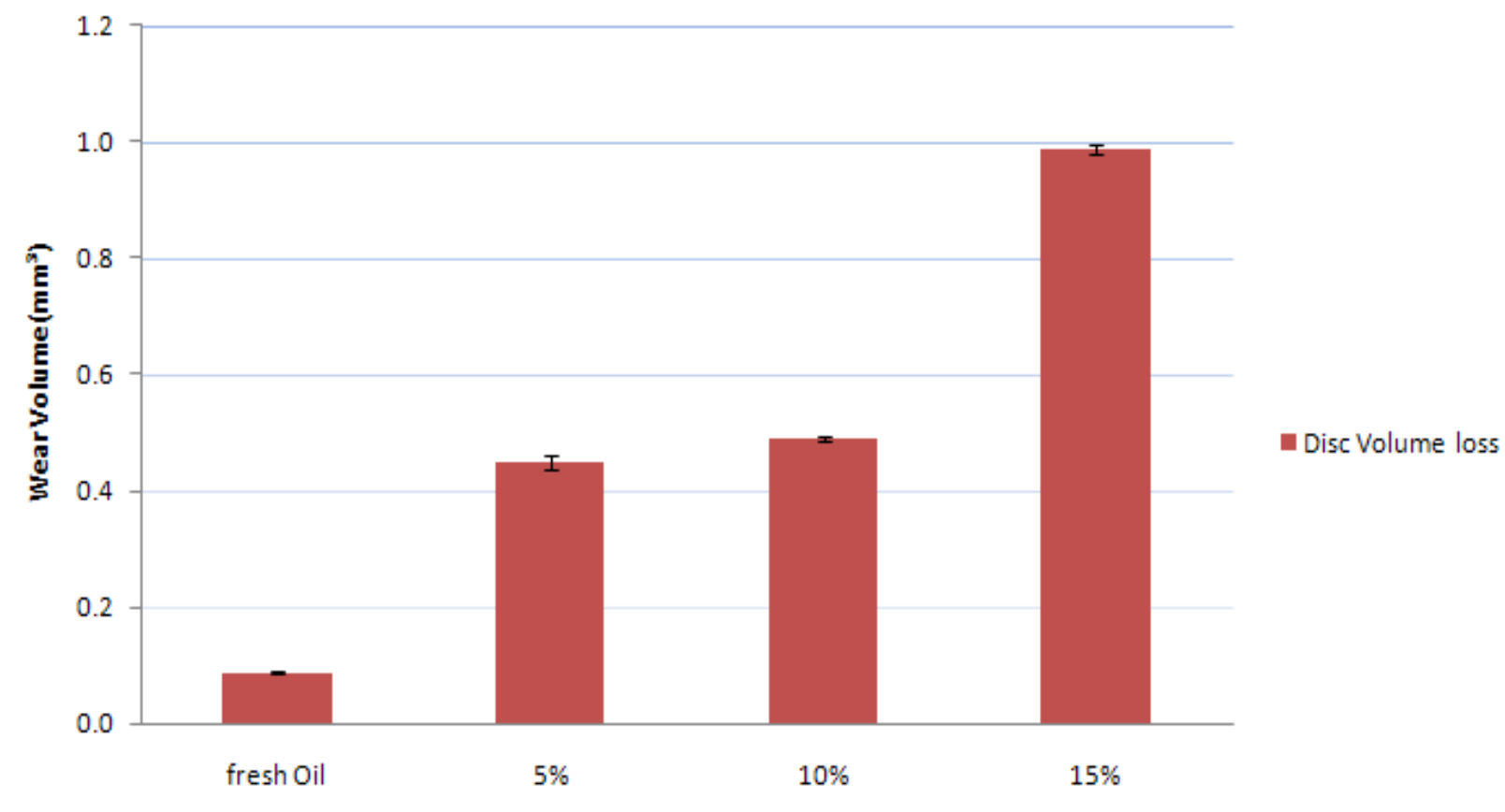

Sand Particles concentration

Figure 6. Wear Results for the Disc for $75-125 \mu \mathrm{m}$ Size Range, under Concentration Variation of Sand Particles 


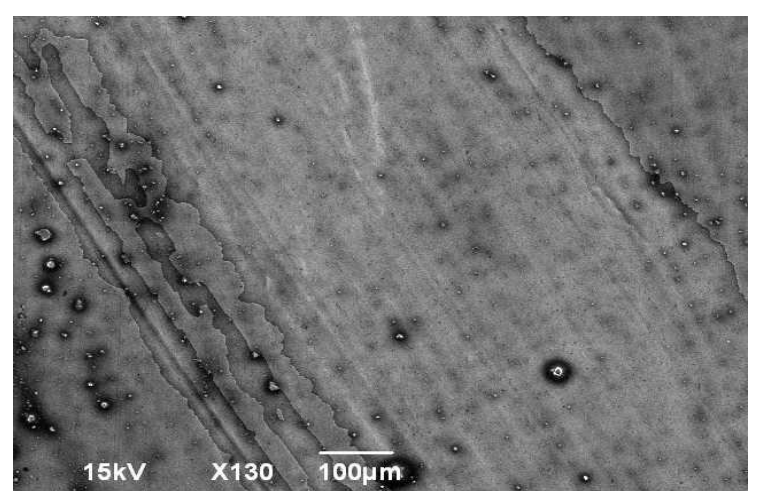

Figure 7. SEM of the Surface of a Stainless Steel Specimen with Purely Sliding.

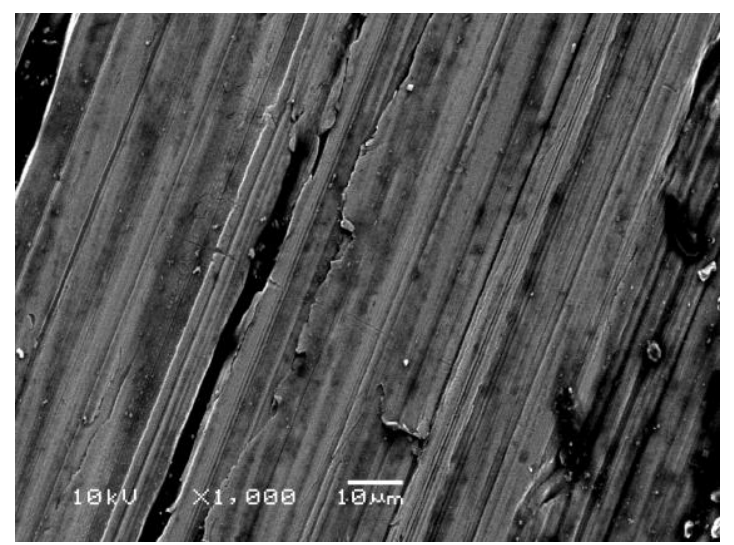

Figure 8, SEM of the Disc of a Stainless Steel Specimen with $10 \%$ Concentration of $75-150 \mu \mathrm{m}$ Size Range, Displaying the Wear Mechanism.

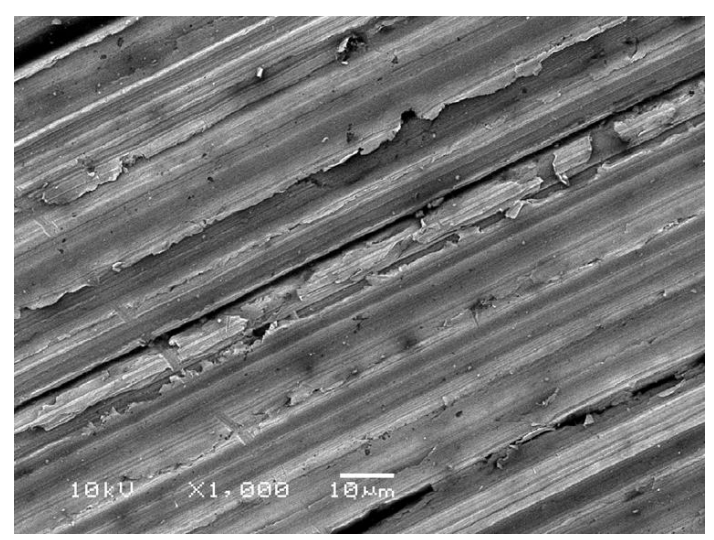

Figure 9. SEM of the Disc of a Stainless Steel Specimen with $15 \%$ Concentration of $75-150 \mu \mathrm{m}$ Size Range

\section{Conclusions}

The current research study showed important results of the friction and wear performance of contaminated lubricated sliding contacts. The impact of the sand particles presence in the lubricated contact is crucial, as they cause high wear and friction rates which result in extra energy consumption, shortened machines lives and loss of materials that translates to extra cost. As the concentration of the sand particles in the lubricated sliding contact increases, the friction and wear rates increased. The particles size was kept constant for all concentrations at $75-125 \mu \mathrm{m}$. The $5 \%$ sand particles showed an increase of $18.86 \%$ friction values, $412.72 \%$ of disc wear values and $11788.48 \%$ for the ball wear volume compared to fresh oil ( $0 \%$ sand particles). The $10 \%$ sand particles showed an increase of $29.65 \%$ friction values, $458.50 \%$ of disc wear values and $20365.18 \%$ for the ball wear volume compared to fresh oil and The $15 \%$ sand particles an increase of $63.66 \%$ friction values, 1028.10 of disc wear values and $30708.83 \%$ for the ball wear volume compared to fresh oil.

\section{References}

1. Baharat Bhushan, 2002, Introduction to Tribology, john Wiley\& sons.

2. M.A.Masen, M.B. de Rooij, D.J. Schipper, Microcontact based modeling of abrasive wear, Wear $258(1-4)$ (2005) 339-348.

3. K.H. Zum Gahr, Modeling of two-body abrasive wear, Wear 124 (1) (1988) 87-103.

4. A.A. Torrance, Modeling abrasive wear, Wear 258 (1-4) (2005) 281-293.

5. Y. Xie, J.A. Williams, The prediction of friction and wear when a soft surface slides against a harder rough surface, Wear 196 (1-2) (1996) 21-34.

6. L. Fang, W. Liu, D. Du, X. Zhang, Q. Xue, Predicting three-body abrasive wear using Monte Carlo methods, Wear 256 (7-8) (2004) 685-694.

7. S.S. Manson, Fatigue: a complex subject-some simple approximation, Experi- mental Mechanics 5 (7) (1965) 193-226.

8. I.M. Hutchings, Tribology: Friction and Wear of Engineering Materials, Edward Arnold, London, 1992.

9. Y. Xie, B. Bhushan, Effects of particle size, polishing pad and contact pressure in free abrasive polishing, Wear 200 (1996) 281-295.

10. D.V. de Pellegrin, A.A. Torrance, E. Haran, Wear mechanisms and scale effects in two body abrasion, Wear 266 (1-2) (2009) 13-20.

11. H. Sin, N. Saka, N.P. Suh, Abrasive wear mechanisms and the grit size effect, Wear 55 (1) (1979) 163-190.

12. A. Misra, I. Finnie, On the size effect in abrasive and erosive wear, Wear 65 (1980) 359-373.

13. R. $G^{\circ}$ ahlin, $\mathrm{S}$. Jacobson, The particle size effect in abrasion studied by controlled abrasive surfaces, Wear 258 (1-4) (1999) 118-125.

14. D.V. de Pellegrin, G. Stachowiak, Simulation of three-dimensional abrasive particles, Wear 258 (1-4) (2005) 208-216.

15. Nathan, G.W.; Jones, J. D. The empirical relationship between abrasive wear and applied conditions. Wear, v.9, n.4 (1966) p.300-309. 